\title{
THE TECHNOLUDIC FILM:IMAGES OF VIDEO GAMES IN MOVIES (1973-2001)
}

\author{
Matteo Bittanti \\ Catholic University of the Sacred Heart, Milan, Italy
}

Abstract: This paper explores the dialectic between video games and film. The researcher analyzed how video games have been depicted, represented, and incorporated into feature-length, commercial movies by viewing, and analyzing 53 video gamerelated films covering the period from 1973 to 2001. These texts were examined and discussed with respect to film genre analysis, structuralism, semiotics, and new media theory. The researcher suggests that convergence between film and cinema led to the emergence of a new film genre, the technoludic film. The neologism combines two different words: technology and ludus, a Latin word for play. Technoludic film is an umbrella term for films that incorporate video games in their narrative. The paper identified and analyzed four possible modes of incorporation of video games into film: commentary, quotation, adaptation, and remediation.The research concludes that there is a merging of languages, narrative strategies, and genres as video games influence films and vice versa.

Key words: Video Games, Cinema, Remediation, Genre Studies, Convergence, Interactive Movies, Avatar, Postmodernism

The recent release of Lara Croft: Tomb Raider represents an important intersection between cinema and video games. Lara Croft, the virtual protagonist of countless action games, has been played by Academy Award winner Angelina Jolie, in a meeting of two of the biggest stars in their respective industries.

Yet, this is not the first of such productions. Other movies based on popular video games, such as Super Mario Bros., Street Fighter, and Mortal Kombat, have been produced in the past. Many more are in production at this very moment.

The original version of this chapter was revised: The copyright line was incorrect. This has been corrected. The Erratum to this chapter is available at DOI: 10.1007/978-0-387-35660-0_65 
Moreover, films are increasingly borrowing ideas, formulas, and conventions from video games. For instance, the opening sequence of Toy Story 2 purports to be located inside the Super Nintendo game based on the movie. Films like The Matrix or eXistenZ present a world in which everyday "reality" turns out to be a computer-generated illusion, a pervasive, complete simulation.

One might ask: Is there a merging of languages-vocabularies, strategies, and genres-as games influence movies and movies influence games? What is the impact of video games on films? To what extent do films and computer or video games offer their own distinct approaches and pleasures?

This paper discusses, explores, and investigates these and other issues related to the ongoing convergence between cinema and video games. It assumes that two media are not simply intersecting: They are converging at many different levels.

Specifically, this paper explores the narratives of convergence. It analyzes how video games have been depicted, represented, and incorporated into feature-length, commercial movies. This task has been accomplished by viewing and analyzing 53 video game-related films covering the period from 1973 to 2001.

After reviewing the available literature on video games-with special attention given to contributions relating to their relationship with cinema-the researcher provides a historical and cultural context for the study.

In particular, he shows how the language, modes of consumption, and stylistic conventions of video games rely on cinema. By emphasizing the numerous parallels between the history and development of the two media, the researcher concludes that video games have inherited some of the features originally found in the earliest manifestations of cinema, the socalled "cinema of attractions."

It also finds in the mutoscope the predecessor of video game, and it explores the relationship between electronic entertainment and Heilig's inventions, like the Sensorama.

The historical discussion into film and video game history is followed by a review of some of the conceptual tools used in the examination of the dialectic between cinema and video games. Specifically, the conceptual overview section focuses on Baudrillard's concept of the simulacrum, Bolter's and Grusin's model of remediation, Genette's notion of intertextuality, and the theory of adaptation. These concepts - which represent the building block for the analysis of the films-have been used, expanded, and extended to critically assess the dialectic between the two media. 
This dialectic has been recognized as a dynamic process in which one proposition - the film-is matched against another-the video game-to bring a third combinatory proposition into being. Although the resulting proposition incorporates elements of both terms, it constitutes something new altogether. The researcher does not simply show that there is a merging of languages, narrative strategies, and genres as video games influence films and film influence games. It argues that the convergence between film and cinema led to the emergence of a brand new film genre, here defined as the technoludic film.

The neologism combines two different words: technology and ludus, a Latin word for play. The term technoludism-first used by the author in a previous study-refers to the technologies of play, most notably video games. Thus, the technoludic film is a cinematic manifestation of technoludism, a narrative of electronic gaming.

The researcher identified and described four possible modes of incorporations of video games into films: commentary, quotation, remediation, and adaptation.

In the technoludic film as commentary and quotation, the source text, i.e., the video game, is subordinated to the film. In both cases, cinema operates as a discourse on video games and makes full use of its language to critique the other medium. Here, the film's dependence to a larger network of cultural texts is implicit: The technoludic film comments on video games, subsuming and grappling with the fascination and fears brought on by this relatively new technology.

Thus, the technoludic film as commentary becomes a screen or a mirror upon which society projects and re-enacts through myth-narratives its deepest anxieties, forbidden desires, escapism from the self, the body, and ultimately, from reality tout court.

A chronological list of technoludic films as commentary includes: Tron (1982), Joysticks (1983), Nightmares (1983), Cloak and Dagger (1984), The Last Starfighter (1984), Hollywood Zap (1987), Toys (1993), Brainscan (1994), Virtual Combat (1994), Arcade (1994), Evolver (1995), The Wizard (1989), The Lawnmower Man (1991), Carver's Gate (1994), Nirvana (1997), Tokyo Eyes (1999), eXistenZ (1999), and Avalon (2001).

The technoludic film also quotes video games. This mode of inclusion is comparable to Genette's intertextual relation, which he defined as the effective co-presence of two texts in the form of quotation, plagiarism, and allusion. Video games are visually evocated as an expressive means of commenting on the fictional world of the alluding film.

This category of films that display video games in one or more scenes for allusive or illustrative purposes includes texts like Soylent Green (1973), Beneath the Valley of Ultravixens (1979), Blade Runner (1982), Android 
(1982), Brother from Another Planet (1984), Superman 3 (1983), D.A.R.Y.L. (1985), Clockers (1997), Titus (2000), The Beach (2000), Center of the World (2001) and many more.

In the technoludic film as remediation and adaptation, cinema is subordinated to the video game. Films do not simply borrows the visual style and narrative strategy of video games, but become spin-offs, tie-ins, and translations of successful products. In both cases, the film's language, function, and content are strictly dependent, if not subordinated, on a secondary text, e.g., the video game.

Cinema is also increasingly adopting video games as a source text rather than a mere theme. In fact, Hollywood is producing more and more translations of popular video games. However, the process of adapting a video game to the big screen, in most cases, has been problematic. This mode of incorporation is analogous to Genette's notion of hypertextuality, i.e., the relation between a text and an anterior hypotext, a text or genre on which it is based and, simultaneously, transforms, modifies, elaborates or subverts. Here, the filmic adaptation of a video game is interpreted as a hypotext's being transformed by a complex series of operations: selection, amplification, concretization, actualization, critique, extrapolation, analogization, popularization, and reculturalization.

A chronological list of cinematic adaptations includes Super Mario Bros (1993), was followed by Double Dragon (1993), Street Fighter: The Movie (1993), Mortal Kombat (1994), Mortal Kombat II: Annihilation (1995), Wing Commander (1999), Lara Croft: Tomb Raider (2001), and Final Fantasy: The Spirits Within (2001). Currently, a dozen of new gamebased film projects are in different stages of production. The increasing popularity of video games adaptations makes this examination particularly timely.

The notion of remediation, formulated by Bolter \& Grusin, accounts for the means of repurposing narrative techniques and modes of representation from historical forms of media and also co-evolving with the existing ones. By experimenting with familiar conventions from other media such as the video game, film has produced new formulas of narrative discourse and modes of representation. Thus, this third category includes movies that embody into their narratives and/or style some of the conventions of video game language. This happens with films like Groundhog Day (1993), Run Lola Run (1998), Being John Malkovich (1999), Dark City (1998), Bio Zombie (1998), Timecode (1999), The Matrix (1999), Toy Story (1995), Toy Story 2 (2000).

The technoludic film as remediation is the outcome of the impressive advances in computer animation and virtual reality technologies. Films that remediate video games become a spectacle, an attraction, and a ludic text, 
both in their aesthetics and in their narrative structure. Cosmetically, they present animations that clearly resemble, deliberately imitate, or directly appropriate those of video games. Moreover, film directors are increasingly using video game conventions to tell their stories. They remediate the diegetic trademarks and the conventions of video games. This happens, for instance, for films that present multi-narratives and reject the medium's traditional linearity. Other films utilize the role-playing metaphor to deliver original and innovative plots.

By using conceptual tools such as structuralism and the model of binary oppositions, the researcher identified the recurrent themes of the technoludic film. The lack of epistemological certainty stands out as a quintessential trait of the genre, along with variants such as the loss of control, the loss of identity, and the loss of boundaries between real and simulation. The narratives revolve around characters who are unable to distinguish between fact and fiction, reality and simulation.

A recurrent feature of the technoludic film is the cinematic figure of the avatar, the player's alter ego. A hybrid, liminal character oscillating between two dimensions, the game world and the real world, the avatar is a technologically charged doppelganger, formed through dynamic interfaces with the computer. The avatar appears to be tailored for an era of ambivalence, slippage, and technological confusion.

It has also emerged that the most prominent themes of technoludic films are crucial tropes of postmodernism. These films, harrowing parables of techno-related horror, are filled with synthetic identities, lethal games, and fantasmatic landscapes. Here, postmodernism is combined with technophobic anxiety: Most films, in fact, mandate escape from technology and the video game world as the only means of holding on to one's humanity.

The continuing narrative preoccupation with video games as a gateway to oblivion confirms that, even 30 years after their introduction, they are still perceived as a problematic, unsettling technology. The author suggests that cinema's incorporation of the visuals and narratives of video games is related to its fear of being supplanted by the new electronic media. In fact, many of the narratives of the technoludic film revolve around virtual characters trying to replace human beings. This can be read as a metaphor of cinema's own fear of being displaced by other technologies of leisure such as video games, Internet, cable, and satellite television.

The paper concludes that the technoludic film is a narrative of ambivalence. On one level, the film industry is resisting the video game invasion by producing movies that clearly condemn electronic entertainment. On another, cinema is assimilating video games into its own discourses and modes of productions. 
As for the value of the study, the researcher introduces the notion of technoludic cinema, a concept that represents a starting point for thinking (or re-thinking) about the ongoing convergence between the two media. The technoludic film is a new film genre that synthesizes some of the elements of both cinema and video games.

The discussion also addresses such topics as the cultural significance of the DVD format, the chimera of interactive movies and the typologies of fruition of film and video games.

By investigating how video games have influenced cinema, the researcher does not simply draw on concepts pertaining to various fields of study, but expands them in various ways.

But, above all, this research is valuable because it is the first academic examination of this transversal phenomenon of media convergence. In fact, an analysis of the dialectic between cinema and video games has not been explicitly addressed by the academic community before.

By examining the shifting accounts of electronic gaming in cinema, this paper provides a critical and historical context for the debate on the relationship between new and old media. 